Check for updates

Cite this: RSC Adv., 2018, 8, 7792

Received 2nd January 2018

Accepted 12th February 2018

DOI: 10.1039/c7ra13761c

rsc.li/rsc-advances

\section{Morphology and pervaporation performance of ionic liquid and waterborne polyurethane composite membranes $\uparrow$}

\begin{abstract}
Tao Xi, (D) Lin Tang, Wentao Hao, Lulu Yao and Peng Cui*
Blending an aromatic-selective ionic liquid (IL, namely 1-ethyl-3-methylimidazolium hexafluorophosphate, [emim] $\left[\mathrm{PF}_{6}\right]$ ) with waterborne polyurethane (WPU) enabled us to obtain [emim] $\left[\mathrm{PF}_{6}\right]$-modified waterborne polyurethane composite membranes. We characterized the structure and properties of the [emim] $\left[\mathrm{PF}_{6}\right] /$ WPU composite membranes by ATR-FTIR, DSC, UV, SEM, EDX, swelling tests, and pervaporation testing. Characterization of the change in the morphology of the membranes in response to the IL loading indicated that a preferential interaction between the IL and soft segments of WPU was induced by hydrogen bonding. This interaction inhibited a potential interaction with benzene (Bz), which initially lowered the permeability. However, at high IL loading, the IL incorporation became ineffective owing to macrophase separation, which caused an increase in the permeability, as indicated by the SEM results. Swelling testing of the [emim] $\left[\mathrm{PF}_{6}\right] / \mathrm{WPU}$ composite membranes showed that the membranes exhibited preferential adsorption of $\mathrm{Bz}$, and the swelling degree of the composite membranes in $\mathrm{Bz}$ solvent increased from $58 \%$ to $98 \%$ and remained almost constant in cyclohexane solvent as the IL content was increased. The [emim] $\left[\mathrm{PF}_{6}\right] / \mathrm{WPU}$ composite membranes enhanced the separation selectivity of Bz/Cy for an IL loading $<10 \mathrm{wt} \%$. The best separation factor was 8.4 , and the total flux was $0.19 \mathrm{~kg}\left(\mathrm{~m}^{2} \mathrm{~h}\right)^{-1}$ $\left(50 \mathrm{wt} \% \mathrm{Bz} / \mathrm{Cy}\right.$ mixtures at $\left.50{ }^{\circ} \mathrm{C}\right)$ at $\mathrm{w}\left([\mathrm{emim}]\left[\mathrm{PF}_{6}\right]\right): \mathrm{w}(\mathrm{WPU})=10: 100$. In addition, the composite membrane exhibited excellent stability over long-term operation. These results demonstrated that the [emim] $\left[\mathrm{PF}_{6}\right] /$ WPU composite membranes could be effective for separation of Bz/Cy mixtures by the pervaporation method.
\end{abstract}

\section{Introduction}

Separation of mixtures of aromatic and aliphatic compounds is one of the most difficult processes in the chemical and petrochemical industries. ${ }^{1-3}$ A typical mixture system, such as a benzene/cyclohexane mixture, features non-polar sixmembered ring compounds, which have very similar chemical and physical properties. The difference in the boiling temperatures of the two components is only $0.6{ }^{\circ} \mathrm{C}$. Aromatic hydrocarbons are important in the chemical industry because they can be used to produce various valuable petrochemicals. Furthermore, the requirements for aromatic content in gasoline and other fuels are becoming stricter and stricter owing to environmental considerations. In recent years, ionic liquids (ILs) as a new class of environment-friendly compounds have

School of Chemistry \& Chemical Engineering, Anhui Key Laboratory of Controllable Chemistry Reaction \& Material Chemical, Hefei University of Technology, Hefei, 230009, People's Republic of China.E-mail: cuipeng@hfut.edu.cn

$\dagger$ Electronic supplementary information (ESI) available: FTIR spectra of pure WPU and $[\mathrm{emim}]\left[\mathrm{PF}_{6}\right] / \mathrm{WPU}$ composite membrane; element mapping of the cross section of $[\mathrm{emim}]\left[\mathrm{PF}_{6}\right] / \mathrm{WPU}$ composite membranes; SEM photographs of cross section of pure WPU and $[\mathrm{emim}]\left[\mathrm{PF}_{6}\right] / \mathrm{WPU}$ composite membranes. See DOI: $10.1039 / \mathrm{c} 7 \mathrm{ra13761c}$ attracted attention for the separation of Bz/Cy mixtures. ${ }^{4-6}$ The properties of ILs, include extremely low vapor pressures, high chemical and thermal stability, and a vast array of possible cation/anion combinations, which give high affinities towards targeted compounds. ${ }^{6-10}$ These features have motivated the application of ILs to extraction/separation of Bz/Cy mixtures, through absorption and membrane processes over the past decade. ${ }^{11-19}$ Although this field has been in development since 2002 the use of ILs as extraction separation agents and supported ionic liquid membranes (SILMs) in industrial applications remains limited owing to certain drawbacks.

Comparison extraction/separation with membrane separation, the high cost and low-processability of extraction separation limit their applications in separation process. So different reports on supported liquid membranes of aromatics from aliphatic hydrocarbon-based ILs have been widely published. For example, Matsumoto et al. ${ }^{19}$ found that supported liquid membranes (SLM) impregnated with $[\mathrm{Bmim}]\left[\mathrm{PF}_{6}\right]$ produced the highest selectivity for aromatic hydrocarbons, particularly benzene. Chakraborty et al. ${ }^{20}$ used membranes that featured pours filled by ILs. It was found that more than $40-70 \%$ recovery of aromatics was possible within 8-24 $\mathrm{h}$ and that the maximum separation factor for Bz was approximately 27 after $24 \mathrm{~h}$ of 
operation. Dong et al. ${ }^{18}$ prepared supported ionic liquid/ polyurethane (PU) membranes by immobilizing ionic liquids on a porous anodic aluminium oxide membrane (AAOM) support that was coated on one side with polyurethane (PU). The separation factor of $\mathrm{Bz}$ to $\mathrm{Cy}$ increased from 5 to 34.4 and the largest PSI of AAOM- $\left[\mathrm{C}_{4} \mathrm{mim}\right]\left[\mathrm{PF}_{6}\right] / \mathrm{PU}$ membrane reached $452.54 \mathrm{~g} \mathrm{~m}^{-2} \mathrm{~h}^{-1}$ at $55^{\circ} \mathrm{C}$ for a $50 \mathrm{wt} \% \mathrm{Bz} / \mathrm{Cy}$ mixtures. However, for these supported liquid membranes without the constraining molecular chains and interactions, the ILs could be expelled from the membrane pores at relatively low transmembrane pressure differentials, which exceeded the capillary forces that held the IL within the support.

Current approaches to preparing stable and efficient ILbased membranes have seen the development of composite membranes involving blends of ILs with common polymers such as polyimides, poly(vinylidene fluoride), and copolymers such as poly(vinylidene fluoride-hexafluoropropylene) or polyether block amides. ${ }^{21-28}$ These membranes are easily prepared by solution casting of a mixture containing the IL, the polymer and a proper solvent in which the IL and polymer are mutually miscible. After evaporation of the solvent, the IL phase is embedded within the polymer matrix, which prevents the expulsion of the IL under a high-pressure differential. In this work, polyurethane was chosen as the polymer matrix because of its low cost, environmental friendliness, diversity of its structures, good permeability, and separation performance for $\mathrm{Bz} / \mathrm{Cy}$ mixtures. ${ }^{29,30}$ Our research group has performed some previous research in this area. ${ }^{29}$ The incorporation of [emim] $\left[\mathrm{PF}_{6}\right]$ into a WPU matrix might affect the microphase structure of the block copolymer. However, there have been no relevant reports about these effects on the separation of Bz/Cy from ILpolymer composite membranes. Hence, it is important to study the influence of the ILs on the phase structure of the polymer and its influence on the pervaporation performance of Bz/Cy mixtures.

In this work, we prepared different mass ratios of [emim] $\left[\mathrm{PF}_{6}\right] /$ WPU composite membranes. The structure, morphology and separation performance of these materials were investigated. These results showed that the composite membranes exhibited excellent stability and high separation performance for Bz/Cy separation. The sorption and diffusivity properties of the solvents in membranes and the correlation with the pervaporation performance of the polymer are reported in this paper. The approach used in this study presents a starting point for the separation of aromatic/aliphatic mixtures by pervaporation, as well as an exploration of potential applications of ILs in polymers.

\section{Experimental}

\subsection{Materials}

An anionic waterborne polyurethane dispersion was synthesized from poly-1,4-butylene adipate glycol (PBA, AR, $M_{\mathrm{n}}=2000$, Qingdao Xinyutian Chemical Co., Ltd., China), isophorone diiso-cyanate (IPDI, AR, Aladdin), 2-ethyl-2-(hydroxymethyl)-1,3propanediol (TMP, AR, Hefei Anke Fine Chemicals Co., Ltd., China). 2,2-Bis(hydroxymethyl) propionic acid (DMPA, AR) was obtained from Xiya Regent. 1-Ethyl-3-methylimidazolium hexafluorophosphate ([emim] $\left.]\left[\mathrm{PF}_{6}\right], \mathrm{AR}\right)$ triethylamine (TEA, AR), dibutyltin dilaurate (DBTDL, AR), butanone (AR), benzene (AR), cyclohexane (AR) were purchased from Sinopharm Chemical Regents. Deionized water was prepared in our lab. The PBA was dried in a vacuum at $120{ }^{\circ} \mathrm{C}$ for $12 \mathrm{~h}$ before use.

\subsection{Membrane preparation}

A predetermined amount of IPDI was added drop-wise to the PBA, reacting in a three-necked round bottom flask and heated at $40{ }^{\circ} \mathrm{C}$ for $1 \mathrm{~h}$. The reaction was performed over a digital magnetic heating/stirrer instrument to obtain a homogeneous mixture. The procedure was continued for $1 \mathrm{~h}$ at $80{ }^{\circ} \mathrm{C}$. In the presence of a DBTDL catalyst, appropriate amounts of DMPA and TMP were added to the flask. The hydrophilic combination and crosslinking reactions were performed for $5 \mathrm{~h}$ at $80^{\circ} \mathrm{C}$. The obtained NCO-terminated prepolymer was cooled to $40{ }^{\circ} \mathrm{C}$, TEA was added to reaction as a neutralization agent for carboxylic groups on the side chain of the prepolymer. A high shearing rate was used to emulsify the solution for $5 \mathrm{~min}$ after deionized water was added to the system. Thereafter, an aqueous solution of EDA was added and stirred for $1 \mathrm{~h}$ to expand the polymer chains; this resulted in a light blue emulsion with a solid content of approximately $10 \mathrm{wt} \%$.

The WPU emulsion was then mixed with the $[\mathrm{emim}]\left[\mathrm{PF}_{6}\right]$ aqueous solution and stirred at $40{ }^{\circ} \mathrm{C}$ for $3 \mathrm{~h}$ to obtain a [emim] $\left[\mathrm{PF}_{6}\right] /$ WPU emulsion. The weight ratios of $[\mathrm{emim}]\left[\mathrm{PF}_{6}\right]$ and WPU were $0: 100,3: 100,5: 100,10: 100,15: 100$ and $20: 100$. The emulsions were then cast onto glass plates and dried in air. The membrane was dried in a vacuum oven at $40{ }^{\circ} \mathrm{C}$ for $8-10 \mathrm{~h}$. The thickness of the membranes was in the range 0.07-0.09 $\mathrm{mm}$. The membranes were named as WPU, WPU-3, WPU-5, WPU-10, WPU-15, and WPU-20, with respect to their weight ratios.

\subsection{Membrane characterization}

Information about the presence of specific functional groups of the prepared membranes was obtained on a Nicolet IR 560 spectrometer with a horizontal ATR accessory equipped with a ZnSe crystal. The thermal properties of $[\mathrm{emim}]\left[\mathrm{PF}_{6}\right] / \mathrm{WPU}$ composite membranes were characterized by a differential scanning calorimeter (TA Q2000, USA). Measurements were performed in a heating/cooling/heating cycle from $-90{ }^{\circ} \mathrm{C}$ to $200{ }^{\circ} \mathrm{C}$ with a heating rate of $10{ }^{\circ} \mathrm{C} \mathrm{min}^{-1}$ under a nitrogen atmosphere. The crystallinity $\left(\chi_{\mathrm{c}}\right)$ was calculated based on the following eqn (1) from the DSC curves.

$$
\chi_{\mathrm{c}}=\frac{\Delta H_{\mathrm{f}}}{\Delta H_{\mathrm{f}}^{*} \phi},
$$

where $\Delta H_{\mathrm{f}}$ and $\Delta H_{\mathrm{f}}^{*}$ represent the fusion enthalpy of the composite membrane and $[\mathrm{emim}]\left[\mathrm{PF}_{6}\right]$ with $100 \%$ crystallinity, respectively. The value of $\Delta H_{\mathrm{f}}^{*}$ was $69.73 \mathrm{~J} \mathrm{~g}^{-1} \cdot{ }^{32}$ The variable $\phi$ is the measured weight fraction of $\left[\mathrm{emim}^{\mathrm{m}}\right]\left[\mathrm{PF}_{6}\right]$.

Transparency was measured with an UV-Vis spectrophotometer (Cary 5000, Agilent). The surface and cross-section morphologies of the membranes were investigated with a scanning electron microscope (SEM, Hitachi, Japan). The surface 
morphology of the membranes was investigated using an atomic force microscope (AFM); (Model 5100, Agilent Tech, USA). The surface roughness of each membrane sample was measured and reported in terms of the roughness average $\left(R_{\mathrm{a}}\right)$.

\subsection{Sorption and degree of swelling measurement}

A weight-gain method was used to determine the sorption equilibrium values. The dry samples were immersed in $\mathrm{Bz} / \mathrm{Cy}$ mixtures or in pure solvents for $48 \mathrm{~h}$ at $50{ }^{\circ} \mathrm{C}$. Then, the samples were taken out from the solution, wiped with tissue paper to remove the adherent liquid. The sorption equilibrium value was defined as:

$$
\mathrm{DS}=\frac{M_{\infty}-M_{0}}{M_{0}},
$$

where $M_{0}$ and $M_{\infty}$ are the initial dry weight of the membrane and the swollen sample at equilibrium, respectively. The composition of the liquid mixture inside the membrane at sorption equilibrium was determined by desorbing liquid on a vacuum line, condensing it in a cold trap, and analysing the composition by gas chromatography in the same way as for the pervaporation. The sorption selectivity was defined as:

$$
\alpha_{\mathrm{s}}=\frac{X_{\mathrm{M}} /\left(1-X_{\mathrm{F}}\right)}{X_{\mathrm{F}} /\left(1-X_{\mathrm{M}}\right)},
$$

where $X_{\mathrm{F}}$ and $X_{\mathrm{M}}$ are the weight fractions of benzene in the feed solution and membrane, respectively.

\subsection{Pervaporation experiments}

The pervaporation experiment apparatus is shown in Fig. 1. Pervaporation experiments were performed at $50{ }^{\circ} \mathrm{C}$ on a homemade device. The effective surface area of the membrane in contact with the feed mixture was $20.2 \mathrm{~cm}^{2}$. The vacuum in the downstream side of the apparatus was maintained $(-0.1009$ $\mathrm{MPa}$ ) with the use of a vacuum pump. After a steady state was attained (approximately $0.5 \mathrm{~h}$ ), the permeate liquid was collected in cold traps immersed in liquid nitrogen. The compositions of each phase were measured by gas chromatography (GC). The permeation results from the of Bz/Cy mixtures during the pervaporation were reproducible. From the pervaporation data, the separation performance of the membranes could be assessed in terms of the total flux $(J)$ and the separation

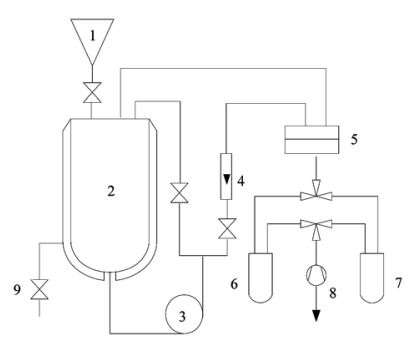

Fig. 1 Schematic view of the pervaporation setup used in this experiment (1) funnel; (2) feed tank; (3) feed pump; (4) flowmeter; (5) plate membrane module; (6), (7) cold trap; (8) vacuum pump; (9) emptying valve. factor $\left(\alpha_{\mathrm{PV}}\right)$, and were calculated respectively, by the following equations:

$$
\begin{gathered}
J=\frac{W}{A t}, \\
\alpha_{\mathrm{PV}}=\frac{X_{\mathrm{P}} /\left(1-X_{\mathrm{F}}\right)}{X_{\mathrm{F}} /\left(1-X_{\mathrm{P}}\right)},
\end{gathered}
$$

where $X_{\mathrm{F}}$ and $X_{\mathrm{P}}$ are the weight fractions of benzene in the feed and permeate, respectively.

\subsection{Membrane stability}

The stabilities of the $[\mathrm{emim}]\left[\mathrm{PF}_{6}\right] / \mathrm{WPU}$ composite membrane were assessed through separation experiments, as described in Section 2.5. The composite membrane was tested at $50{ }^{\circ} \mathrm{C}$ with a feed of $50 \mathrm{wt} \% \mathrm{Bz}$. The tests were repeated 24 times.

\section{Results and discussion}

\subsection{Transparency of the composite membranes}

The transparency of pure WPU and $\left[\mathrm{emim}^{-}\right]\left[\mathrm{PF}_{6}\right] / \mathrm{WPU}$ composite membranes was tested with a UV-Vis spectrophotometer, and the results are presented in Fig. 2a. The $[\mathrm{emim}]\left[\mathrm{PF}_{6}\right]$ membranes were opaque with a low-visible light transmittance, and pure WPU was optically transparent with approximately $88 \%$ light transmittance (Fig. 2a-WPU). As the weight fraction of [emim] $\left[\mathrm{PF}_{6}\right]$ was increased in the WPU membranes, the transparency of the $[\mathrm{emim}]\left[\mathrm{PF}_{6}\right] /$ WPU composite membranes considerably decreased. This result suggested that the macrophase separation of the $[\mathrm{emim}]\left[\mathrm{PF}_{6}\right] /$ WPU composite membranes contributed to light refraction, thereby resulting in low-light transmission of the $[\mathrm{emim}]\left[\mathrm{PF}_{6}\right] /$ WPU composite membranes. The light transmittance values
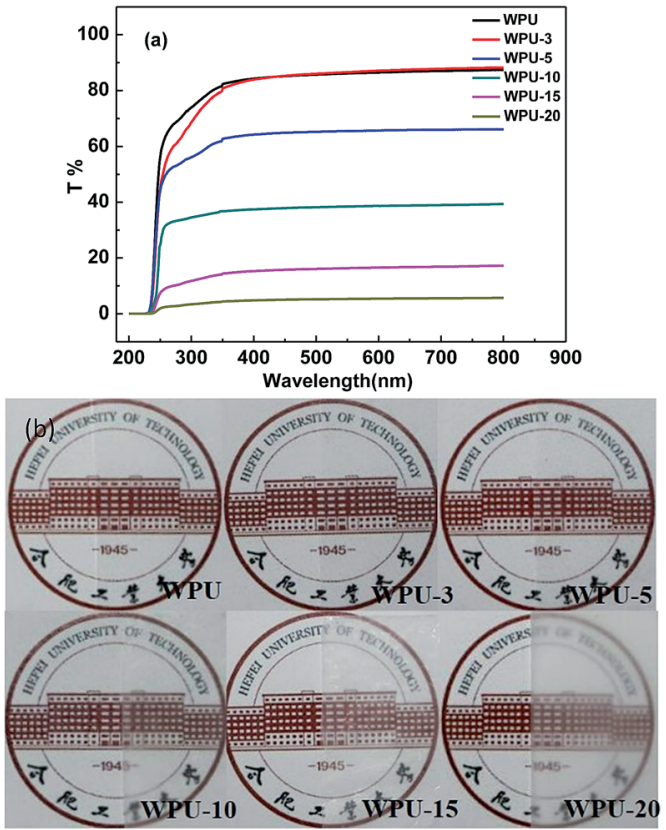

Fig. 2 UV-visible absorption spectrum and appearance of pure WPU and [emim] $\left[\mathrm{PF}_{6}\right] / \mathrm{WPU}$ composite membranes. 
were in good agreement with their appearance, as shown in Fig. 2b.

\subsection{Characterizations of WPU and $[\mathrm{emim}]\left[\mathrm{PF}_{6}\right] / \mathrm{WPU}$ composite membranes}

The FTIR spectra in Fig. 3 all showed bands in the range of 3300-3500 and at $\sim 1730$, and $\sim 1550 \mathrm{~cm}^{-1}$; these bands were characteristic of the urethane groups from WPU. From WPU to WPU-15, these three bands generally decreased because of the gradual decrease of WPU content. Features above $3000 \mathrm{~cm}^{-1}$ were attributed to $\mathrm{C}-\mathrm{H}$ vibration modes of the imidazolium ring (aliphatic side). Peaks at 3183 and $3168 \mathrm{~cm}^{-1}$ appeared because of $\nu_{\mathrm{s}}(\mathrm{C}-\mathrm{H})$ and $\nu_{\text {as }}(\mathrm{C}-\mathrm{H})$ vibration modes of $\mathrm{C}^{4,5} \mathrm{H}$ group. The peaks at $3132 \mathrm{~cm}^{-1}$ belonged to the $\nu(\mathrm{C}-\mathrm{H})$ vibration mode of $\mathrm{C}^{2} \mathrm{H}$ bond. The broad band appearing at $841 \mathrm{~cm}^{-1}$ and a short spike at $557 \mathrm{~cm}^{-1}$ were attributed to the stretching vibration of the $\mathrm{PF}_{6}{ }^{-}$anion. The peaks at 1613 and $1572 \mathrm{~cm}^{-1}$ were assigned to stretching vibrations of $\mathrm{C}=\mathrm{C}$ groups from the imidazolium ring. The peak at $750 \mathrm{~cm}^{-1}$ was assigned to the $\mathrm{CH}_{2}$ vibration of alkyl chains (imidazolium ring). The FT-IR spectrum of the composite membranes [as described in the ESI, S1(a)†] shows that WPU exhibited a shift of the stretching vibration of the $\mathrm{C}=\mathrm{O}$ group towards lower frequencies from 1730 to $1715 \mathrm{~cm}^{-1}$ (i.e. a red shift). A similar trend was observed in the spectra of $\nu \mathrm{PF}$ and $\nu \mathrm{C}^{2} \mathrm{H}$ frequencies [S1(b) and (c) $\left.\dagger\right]$. Considerable red shifts of $\nu \mathrm{C}^{2} \mathrm{H}, \nu \mathrm{PF}$, and $\nu \mathrm{C}=\mathrm{O}$ frequencies were observed, revealing $\mathrm{H}$-bond like interactions between the $\mathrm{C}^{2} \mathrm{H}$ cation site and proton-accepting groups, i.e., $-\mathrm{C}=\mathrm{O}$ group from WPU and $\mathrm{P}-\mathrm{F}$ group from anion. ${ }^{31} \mathrm{~A}$ possible interaction model in the [emim $]\left[\mathrm{PF}_{6}\right] / \mathrm{WPU}$ composite membranes is depicted in Fig. 4.

\subsection{Thermal properties of the membranes}

The thermal properties of the membranes containing the [emim] $\left[\mathrm{PF}_{6}\right]$ in WPU were studied by DSC analysis (Fig. 5). Table 1 shows the glass transition temperature $\left(T_{\mathrm{g}}\right)$, melting temperature $\left(T_{\mathrm{m}}\right)$, and enthalpy of fusion $\Delta H_{\mathrm{f}}$ of the composite membranes studied in this work and values taken from the literature. For pure WPU two dominant glass transitions were present, in which -53.1 and $63{ }^{\circ} \mathrm{C}$ from the micro-Brownian segmental motion of soft segment and hard segment of WPU, this shows the WPU membrane has two phases. Upon addition

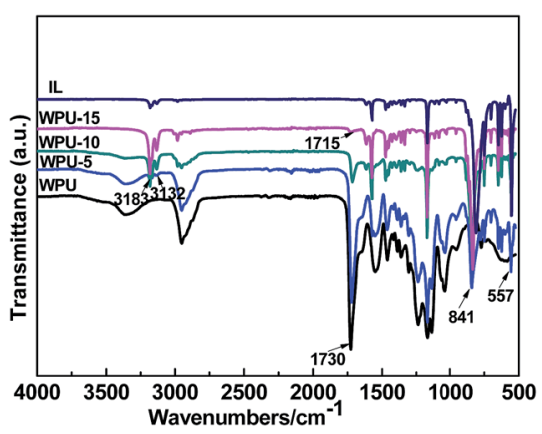

Fig. 3 FTIR spectra of pure WPU and [emim] $\left[\mathrm{PF}_{6}\right] / \mathrm{WPU}$ composite membranes.

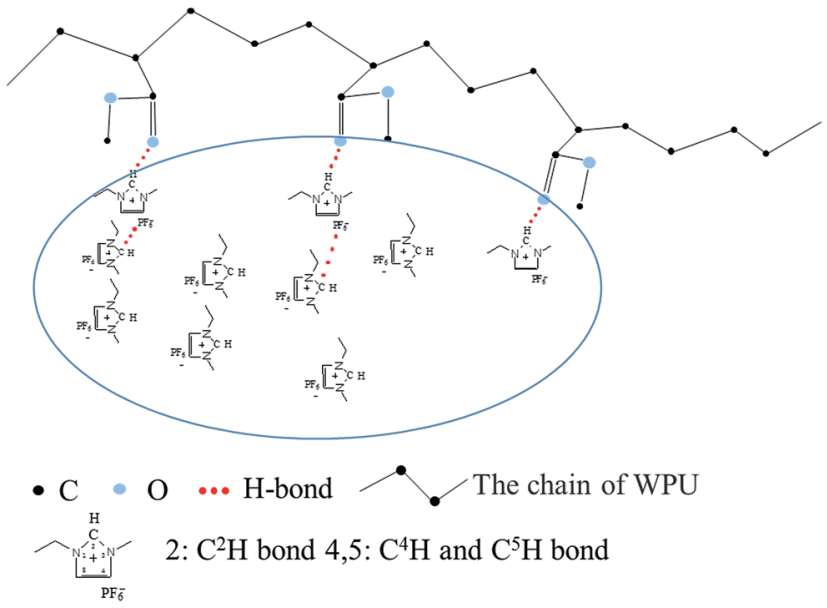

Fig. 4 Possible model of interactions in [emim] $\left[\mathrm{PF}_{6}\right] / \mathrm{WPU}$ composite membranes.

of $[$ emim $]\left[\mathrm{PF}_{6}\right]$, membranes containing $[\mathrm{emim}]\left[\mathrm{PF}_{6}\right]$ exhibited a sharp melting peak at approximately $54{ }^{\circ} \mathrm{C}$. Furthermore, the $T_{\mathrm{g}} \mathrm{s}$ of the soft segments shifted to higher temperature at first and then decreased, as the IL loading was increased. The increase of the glass transition temperature indicated that [emim $]\left[\mathrm{PF}_{6}\right]$ and WPU interacted together, which restricted the chain mobility owing to the fractional free volume change, ${ }^{36}$ and this effect reduced permeability. However, for IL loading $>10 \mathrm{wt} \%$, small islands of the ionic liquid were likely dispersed throughout the block copolymer matrix and could not markedly influence the segmental motion of soft molecular chains. This effect would lead to the formation of IL swollen micro-sized domains and an increase of amorphous portions of the polymer where transport of components occurred.

The DSC measurements also gave the melting enthalpy $\left(\Delta H_{\mathrm{f}}\right)$ and degree of crystallinity $\left(\chi_{\mathrm{c}}\right)$, as shown in Table 1 . The $\Delta H_{\mathrm{f}}$ of the $[\mathrm{emim}]\left[\mathrm{PF}_{6}\right] / \mathrm{WPU}$ composite membrane was in the range of 1.128-7.515 $\mathrm{J} \mathrm{g}^{-1}$, while that for $[\mathrm{emim}]\left[\mathrm{PF}_{6}\right]$ was $69.73 \mathrm{~J} \mathrm{~g}^{-1}$. According to eqn (1), as the IL content was increased, the crystallinity first increased then decreased. The glass transition temperature $\left(T_{\mathrm{g}}\right)$ and degree of crystallinity $\left(\chi_{\mathrm{c}}\right)$ changed markedly with IL loading and exhibited similar trends. This trend is typical of permeation behaviour through membranes.

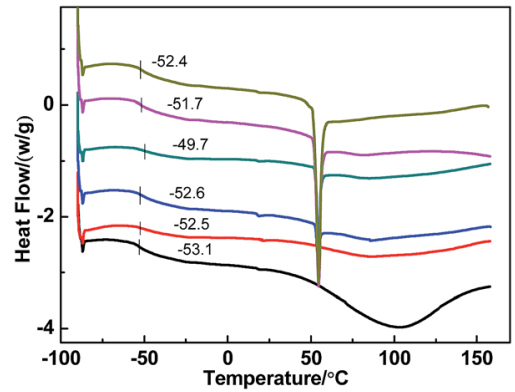

Fig. 5 DSC thermograms of pure WPU and [emim] $\left[\mathrm{PF}_{6}\right] / \mathrm{WPU}$ composite membranes. 
Table 1 Glass transition temperature $\left(T_{g}\right)$, crystalline melting temperature $\left(T_{m}\right)$, and crystalline fusion enthalpy $\left(\Delta H_{m}\right)$ for the [emim] $\left[\mathrm{PF}_{6}\right] /$ WPU composite membranes

\begin{tabular}{llllll}
\hline Sample & $\begin{array}{l}{[\mathrm{emim}]\left[\mathrm{PF}_{6}\right]} \\
\text { content } / \mathrm{wt} \%\end{array}$ & $T_{\mathrm{g}} \mathrm{S} /{ }^{\circ} \mathrm{C}$ & $T_{\mathrm{m}} /{ }^{\circ} \mathrm{C}$ & $\Delta H_{\mathrm{f}} / \mathrm{J} \mathrm{g}^{-1}$ & $\chi_{\mathrm{c}} / \%$ \\
\hline WPU-0 & 0 & 53.1 & - & - & - \\
WPU-3 & 3 & 52.5 & - & - & - \\
WPU-5 & 5 & 52.6 & 54.1 & 1.128 & 32.4 \\
WPU-10 & 10 & 49.7 & 54.6 & 4.213 & 60.4 \\
WPU-15 & 15 & 51.7 & 54.5 & 6.192 & 59.2 \\
WPU-20 & 20 & 52.4 & 54.5 & 7.515 & 53.8 \\
{$[$ emim] $]\left[\mathrm{PF}_{6}\right]$} & 100 & ${ }^{a}$ & $59.7^{b}$ & $69.73^{b}$ & \\
${ }^{a}$ Not available. ${ }^{b}$ Ref. 32. & & & &
\end{tabular}

Thus, components might transport through the $[\mathrm{emim}]\left[\mathrm{PF}_{6}\right]$ WPU composite membranes at soft segments and at IL regions.

On the basis of the reported FTIR, DSC results, we concluded that most of the $[\mathrm{emim}]\left[\mathrm{PF}_{6}\right]$ was distributed in soft segments domains and interacted with the active groups $(-\mathrm{C}=\mathrm{O})$ present in the soft segment domains through hydrogen bonding.

\subsection{Morphology of the composite membranes}

Fig. 6(a)-(d) shows SEM micrographs of the surface section of pure WPU and $[\mathrm{emim}]\left[\mathrm{PF}_{6}\right] / \mathrm{WPU}$ composite membranes. SEM micrographs showed that the surface of the pure WPU membrane was compact and flat. Upon addition of the IL, the surface morphology of the composite membranes become rough. This change was attributed to the fact that the addition of $[\mathrm{emim}]\left[\mathrm{PF}_{6}\right]$ disrupted the order of the polyurethane chain segments, leading to roughness of the composite membrane surface. AFM results quantitatively demonstrated the above conclusion. As shown in Fig. 7, for the pure WPU membrane, the arithmetic mean of the surface roughness $\left(R_{\mathrm{a}}\right)$ was $0.81 \mathrm{~nm}$; as the $[\mathrm{emim}]\left[\mathrm{PF}_{6}\right]$ loading was increased, the $R_{\mathrm{a}}$ values increased to $1.35,3.57$, and $6.89 \mathrm{~nm}$ respectively; however, macrophase separation at higher IL loading caused the resulting $[\mathrm{emim}]\left[\mathrm{PF}_{6}\right]$ to precipitate at the external surface of the membrane and form tiny droplets as a thin film. The

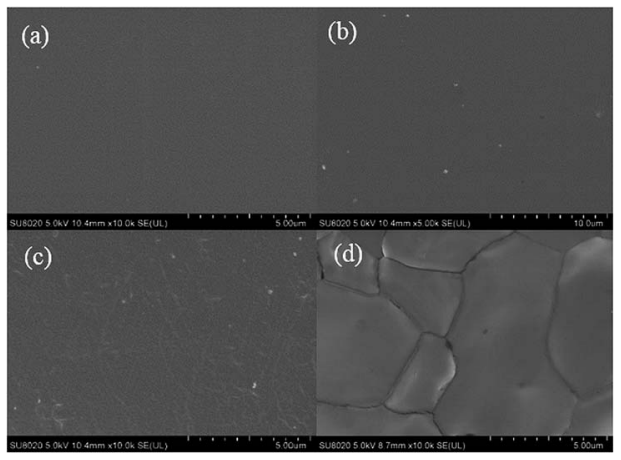

Fig. 6 SEM photographs of surface of pure WPU and [emim] $\left[\mathrm{PF}_{6}\right] /$ WPU composite membranes: (a) pure WPU surface, (b) surface of WPU-5, (c) surface of WPU-10, (d) surface of WPU-15.

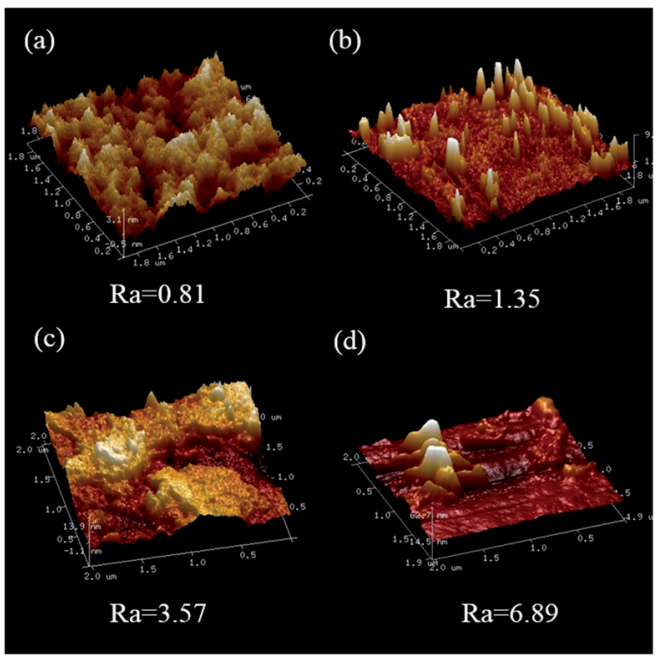

Fig. 7 AFM microphotographs of the surface of WPU (a), WPU-5 (b), WPU-10 (c), and WPU-15 (d).

cross-sectional morphology of the $[\mathrm{emim}]\left[\mathrm{PF}_{6}\right] / \mathrm{WPU}$ composite membranes is shown in S2(a)-(d). $\dagger$ The distribution of [emim] $\left[\mathrm{PF}_{6}\right]$ was nearly homogeneous for IL loading $<10 \mathrm{wt} \%$. To visualize the distribution of IL in the polymer, EDS elemental mapping of phosphorus, which is representative of the IL distribution in the $\left[\mathrm{emim}^{-}\left[\mathrm{PF}_{6}\right] / \mathrm{WPU}\right.$ composite membranes, was conducted. The mapping revealed that the IL was homogenously dispersed throughout the matrix, rather than forming separate IL domains ( $\mathrm{S} 3 \dagger)$. However, at high IL $>10 \mathrm{wt} \%$, small islands of the IL were dispersed throughout the block copolymer matrix and formed separate IL domains $[\mathrm{S} 2(\mathrm{~d}) \dagger]$.

\subsection{Swelling and sorption behaviour of the composite membranes}

Table 2 shows the variation of the equilibrium DS values and sorption of membranes in $\mathrm{Bz}, \mathrm{Cy}$, and $\mathrm{Bz} / \mathrm{Cy}(50 / 50)$ mixtures in the composite membranes. The swelling results showed that the equilibrium DS value of $\mathrm{Cy}$ to the composite membranes was approximately $3.7 \%$, and this remained constant. However, the results of swelling also showed that the equilibrium DS values of the composite membranes towards Bz increased from $58 \%$ to $98 \%$. This swelling behavior follows sorption which IL represents the high affinity towards aromatics than aliphatic hydrocarbons as reported elsewhere. ${ }^{14}$

It is well known that differences in the solubility of solvents in the polymer membrane and differences in the diffusivity of solvents in a polymer membrane in the solution-diffusion mode ${ }^{30,33}$ are strongly related to their permselectivity. ${ }^{34,35}$ It is very important to determine the sorption selectivity and diffusion selectivity to elucidate the separation mechanism of Bz/Cy mixtures of benzene through $\left[\mathrm{emim}^{-}\left[\mathrm{PF}_{6}\right] / \mathrm{WPU}\right.$ composite membranes. Hence, to discuss the Bz-permselectivity of $\mathrm{Bz} / \mathrm{Cy}$ mixtures of benzene through $\left[\mathrm{emim}^{-}\right]\left[\mathrm{PF}_{6}\right] / \mathrm{WPU}$ composite membranes from the viewpoint of the solution-diffusion mechanism, both the sorption selectivity and the diffusion 
Table 2 Effects of the [emim] $\left[\mathrm{PF}_{6}\right]$ content on swelling and sorption behaviour of the membranes

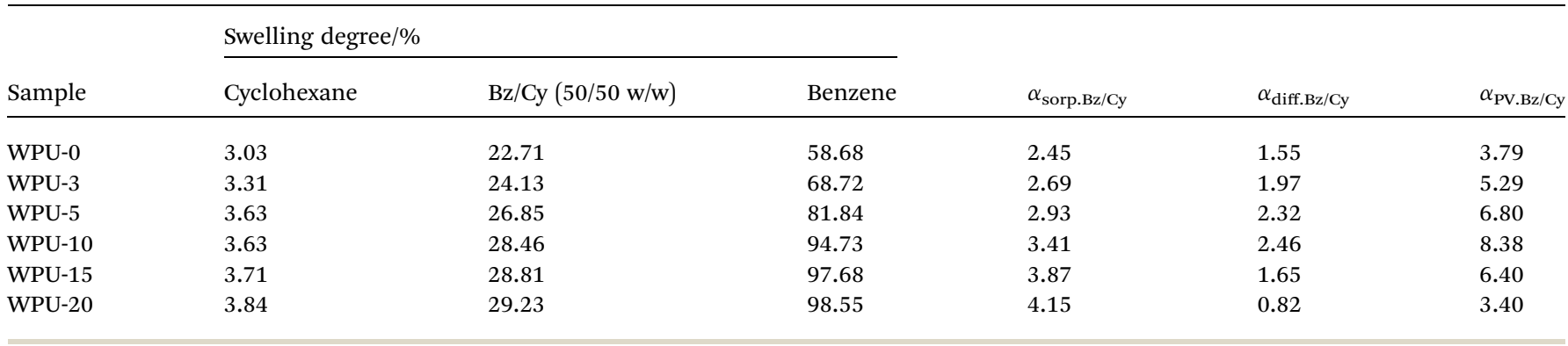

selectivity must be determined. The sorption selectivity, $\alpha_{\text {sorp.Bz/ }}$ Cy was determined from eqn (2), whereas the diffusion selectivity, $\alpha_{\text {diff.Bz/Cx }}$, could be calculated from eqn (6) using eqn (3) and (5):

$$
\alpha_{\text {diff.Bz/Cy }}=\alpha_{\mathrm{PV} . \mathrm{Bz} / \mathrm{Cy}} / \alpha_{\text {sorp.Bz/Cy }}
$$

In Table 2, the results of the sorption selectivity and diffusion selectivity showed that the sorption selectivity and diffusion selectivity clearly changed as the IL content was increased in the composite membranes. As the IL loading was increased, the diffusion selectivity increases at first then decreased reaching a maximum of 2.5 , which was 1.6 times as large as that of the pure WPU membrane. The sorption selectivity increased together with the increase of IL content and a maximum of 4.2 was achieved. It can be seen that the sorption selectivity was higher than the diffusion selectivity in all membranes, which suggested that the separation of $\mathrm{Bz} / \mathrm{Cy}$ was mainly governed by sorption selectivity.

\subsection{Pervaporation performance of the composite membranes}

Fig. 8 shows the effects of $[\mathrm{emim}]\left[\mathrm{PF}_{6}\right]$ content on total permeation flux and separation factor for $\mathrm{Bz} / \mathrm{Cy}$ mixtures with $50 \mathrm{wt} \%$ benzene by pervaporation. As shown in Fig. 7 , when the content of IL increased from $0 / 100$ to $10 / 100$, the pervaporation separation factor continued to increase and the maximum reached 8.4, which is 2.2 times larger than that of the pure WPU membrane. However, the separation factor decreased at higher IL loading, and at its lowest was even lower than that of the pure

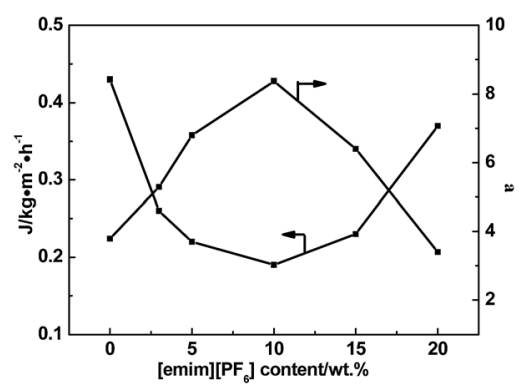

Fig. 8 Effect of [emim] $\left[\mathrm{PF}_{6}\right]$ content in membranes on pervaporation performance for $\mathrm{Bz} / \mathrm{Cy}$ mixtures with $50 \mathrm{wt} \%$ benzene at $50{ }^{\circ} \mathrm{C}$.
WPU membrane. The results of the pervaporation analysis also showed that the flux of the composite membranes first decreased then increased. The resulting separation performance was a trade-off between the pervaporation separation factor and flux.

Because the IL has an affinity for benzene, the separation factor was improved as the IL content increases. However, the resistance was greater when benzene was separated from the ionic liquid phase area; furthermore, as the glass transition temperature of the polyurethane soft segment increased the free volume of the corresponding polyurethane phase decreased, ${ }^{36}$ which led to greater diffusion resistance of $\mathrm{Bz} / \mathrm{Cy}$, resulting in a decrease of flux. For an IL loading $>10 \mathrm{wt} \%$, the possibly ineffective IL incorporation owing to macrophase separation reduced the separation performance. The factors that contributed to the enhancement in permeability through the composite membranes could be the result of an increase in the area where transport of components occurred owing to morphological changes, i.e., a decrease in the degree of crystallinity, and decrease of the glass transition temperature as a result of the fractional free volume change.

\subsection{Stability of composite membranes}

Membrane stability is one of the most important factors for the performance of commercial separation applications. To investigate the pervaporation performance stability of membranes, experiments were performed at $50{ }^{\circ} \mathrm{C}$ for $24 \mathrm{~h}$ with $\mathrm{Bz} / \mathrm{Cy}$ mixtures containing $50 \mathrm{wt} \%$ benzene. The results are shown in Fig. 9 and we can see that the separation factors and

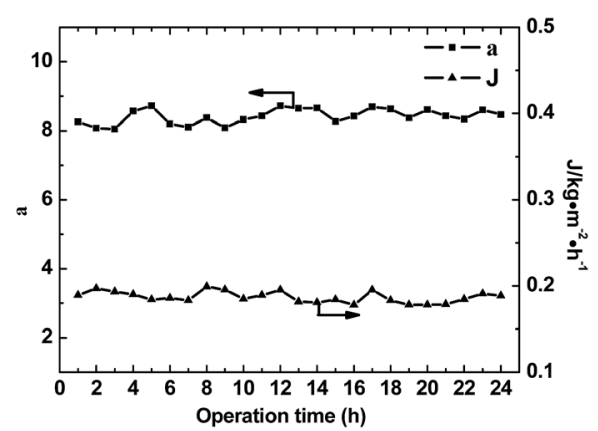

Fig. 9 Stabilities of the composite membranes in the separation of Bz/ Cy mixtures with $50 \mathrm{wt} \% \mathrm{Bz}$ at $50{ }^{\circ} \mathrm{C}$. 
Table 3 Comparison of separation performance (50 wt\% Bz/Cy) for various membranes

\begin{tabular}{|c|c|c|c|c|c|c|}
\hline Membrane materials & $\begin{array}{l}\text { Bz content } \\
\text { (wt\%) }\end{array}$ & $\begin{array}{l}\text { Feed temperature } \\
\left({ }^{\circ} \mathrm{C}\right)\end{array}$ & $\begin{array}{l}\text { Separation } \\
\text { factor }\end{array}$ & $\begin{array}{l}\text { Permeation flux } \\
\left(\mathrm{g} \mathrm{m}^{-2} \mathrm{~h}^{-1}\right)\end{array}$ & PSI $\left(\mathrm{g} \mathrm{m}^{-2} \mathrm{~h}^{-1}\right)$ & Reference \\
\hline PU(0)-1000 & 5 & 25 & 4.6 & 189 & 869.4 & 30 \\
\hline $\mathrm{P}(\mathrm{AN}-b-\mathrm{MA})$ & 50 & 30 & 10.5 & 70 & 735 & 38 \\
\hline Boltorn W3000/ceramic & 50 & 40 & 4.1 & 278 & 861.8 & 39 \\
\hline CMS/PVA & 50 & 50 & 20.79 & 71.99 & 1315.9 & 40 \\
\hline
\end{tabular}

permeation flux of the composite membrane with $10 \mathrm{wt} \%$ $[\mathrm{emim}]\left[\mathrm{PF}_{6}\right]$ remained stable throughout the test period. Owing to their unique properties, such as negligible vapor pressures, the leakage of the IL from the composite membranes was negligible. However, ILs also interact with the polymer molecular chains and encapsulated by WPU matrix. The membranes therefore exhibited good long-term stability when used for the separation of $\mathrm{Bz} / \mathrm{Cy}$ mixtures.

\subsection{Comparison of separation performance}

The pervaporation performances of the $\left[\mathrm{emim}^{-}\left[\mathrm{PF}_{6}\right] / \mathrm{WPU}\right.$ composite membranes for $\mathrm{Bz} / \mathrm{Cy}$ mixtures were compared with the reported membranes. As shown in Table 3, although the testing conditions were different, to some extent, the results of this study have demonstrated that the separation capacity of the $\left[\mathrm{emim}^{-}\left[\mathrm{PF}_{6}\right] / \mathrm{WPU}\right.$ composite membranes is comparable with reference data. As shown in the table, the pervaporation separation index (PSI) of the $[\mathrm{emim}]\left[\mathrm{PF}_{6}\right] / \mathrm{WPU}$ composite membranes was higher than that of $\mathrm{PU}(0)-1000$, NBR/hydrin/ PMMA, P(AN- $b$-MA), CMS/PVA and AAOM- $\left[\mathrm{C}_{4}\right.$ mim $] \mathrm{PF}_{6} / \mathrm{PU}$. This result indicates good potential for pervaporation separation of $\mathrm{Bz} / \mathrm{Cy}$ mixtures.

\section{Conclusions}

We prepared $[\mathrm{emim}]\left[\mathrm{PF}_{6}\right] / \mathrm{WPU}$ composite membranes and characterized their structure and performance by FTIR, SEM, EDX, DSC, UV, and pervaporation separation of $\mathrm{Bz} / \mathrm{Cy}$ mixtures. We concluded that most of the $\left[\mathrm{emim}^{\mathrm{m}}\right]\left[\mathrm{PF}_{6}\right]$ was distributed in soft segment domains and interacted with active groups (i.e. $-\mathrm{C}=\mathrm{O}$ ) present in the soft segment domains via hydrogen bonding, as indicated by the FTIR and DSC results. The swelling experiment results of the membranes demonstrated: the equilibrium DS value of cyclohexane for the composite membranes was approximately $3.7 \%$; however, the equilibrium DS value of the composite membranes for benzene increased from $58 \%$ to $98 \%$. All swelling behaviours suggested that the $[\mathrm{emim}]\left[\mathrm{PF}_{6}\right] / \mathrm{WPU}$ composite membranes had better affinity for $\mathrm{Bz}$ than that for $\mathrm{Cy}$. Moreover, we found that the increase of $\left[\mathrm{emim}^{-}\left[\mathrm{PF}_{6}\right]\right.$ content yielded higher selectivity and lower total fluxes to benzene, and experiments also showed that $[\mathrm{emim}]\left[\mathrm{PF}_{6}\right] / \mathrm{WPU}$ composite membranes was more selective for $\mathrm{Bz}$ than for Cy in terms of the difference in sorption selectivity parameter. The $\left[\mathrm{emim}^{-}\right]\left[\mathrm{PF}_{6}\right] / \mathrm{WPU}$ composite membranes exhibited the highest separation factor of 8.4 with a permeation flux of $0.19 \mathrm{~kg}\left(\mathrm{~m}^{2} \mathrm{~h}\right)^{-1}$ at $323 \mathrm{~K}$ for $\mathrm{Bz} / \mathrm{Cy}(50 / 50 \mathrm{wt} \%)$ mixtures. The results of the stability experiments indicated that the composite membranes exhibited excellent stability.

\section{Conflicts of interest}

There are no conflicts to declare.

\section{Acknowledgements}

We gratefully acknowledge the grants from the Natural Science Foundation of China (No. 21476055) and Hefei University of Technology to support this work. We thank RSC-editing (https://rsc-editing.org/) for its linguistic assistance during the preparation of this manuscript.

\section{References}

1 T. Wu, N. Wang, J. Li, L. Wang, W. Zhang, G. Zhang and S. Ji, J. Membr. Sci., 2015, 486, 1-9.

2 C. P. Ribeiro, B. D. Freeman, D. S. Kalika and S. Kalakkunnath, J. Membr. Sci., 2012, 390, 182-193.

3 S. V. Kononova, R. V. Kremnev, E. I. Suvorova, Y. G. Baklagina, B. Z. Volchek, P. Uchytil and J. Reznickova, J. Membr. Sci., 2015, 477, 14-24.

4 C. P. Ribeiro Jr, B. D. Freeman, D. S. Kalika and S. Kalakkunnath, Ind. Eng. Chem. Res., 2012, 52(26), 89068916.

5 M. T. Ravanchi, T. Kaghazchi and A. Kargari, Desalination, 2009, 235(1), 199-244.

6 Y. Wang, Q. L. Deng, G. Z. Fang, M. F. Pan, Y. Yu and S. Wang, Anal. Chim. Acta, 2012, 712, 1-8.

7 H. Han, Q. Wang, X. Liu and S. Jiang, J. Chromatogr. A, 2012, 1246, 9-14.

8 C. C. Liu, Q. L. Deng, G. Z. Fang, H. L. Liu, J. H. Wu, M. F. Pan and S. Wang, Anal. chim. Acta, 2013, 804, 313-320.

9 G. Zarca, W. J. Horne, I. Ortiz, A. Urtiaga and J. E. Bara, J. Membr. Sci., 2016, 515, 109-114.

10 Z. Lei, C. Dai and B. Chen, Chem. Rev., 2013, 114(2), 12891326.

11 S. Corderí, E. J. González, N. Calvar and Á. Domínguez, J. Chem. Thermodyn., 2012, 53, 60-66. 
12 F. Zhang, Y. Li, L. Zhang, Z. Zhou, W. Sun and Z. Ren, Ind. Eng. Chem. Res., 2016, 55(3), 747-756.

13 T. Zhou, Z. Wang, L. Chen, Y. Ye, Z. Qi, H. Freund and K. Sundmacher, J. Chem. Thermodyn., 2012, 48, 145-149.

14 I. Domínguez, E. J. González and Á. Domínguez, Fuel Process. Technol., 2014, 125, 207-216.

15 N. Calvar, I. Domínguez, E. Gómez and Á. Domínguez, Chem. Eng. J., 2011, 175, 213-221.

16 F. Peng, C. Hu and Z. Jiang, J. Membr. Sci., 2007, 297(1), 236242.

17 J. Chen, J. Li, Y. Lin and C. Chen, J. Appl. Polym. Sci., 2009, 112(4), 2425-2433.

18 Y. Dong, H. Guo, Z. Su, W. Wei and X. Wu, Chem. Eng. Process., 2015, 89, 62-69.

19 M. Matsumoto, K. Ueba and K. Kondo, Desalination, 2009, 241(1-3), 365-371.

20 M. Chakraborty, D. Dobaria and P. A. Parikh, Pet. Sci. Technol., 2012, 30(23), 2504-2516.

21 P. Bernardo, J. C. Jansen, F. Bazzarelli, F. Tasselli, A. Fuoco, K. Friess and G. Clarizia, Sep. Purif. Technol., 2012, 97, 73-82.

22 H. Z. Chen, P. Li and T. S. Chung, Int. J. Hydrogen Energy, 2012, 37(16), 11796-11804.

23 M. Fallanza, A. Ortiz, D. Gorri and I. Ortiz, J. Membr. Sci., 2013, 444, 164-172.

24 K. Friess, J. C. Jansen, F. Bazzarelli, P. Izák, V. Jarmarová, M. Kačírková and P. Bernardo, J. Membr. Sci., 2012, 415, 801-809.

25 Y. Gu, E. L. Cussler and T. P. Lodge, J. Membr. Sci., 2012, 423, 20-26.
26 J. C. Jansen, K. Friess, G. Clarizia, J. Schauer and P. Izak, Macromolecules, 2010, 44(1), 39-45.

27 S. Kanehashi, M. Kishida, T. Kidesaki, R. Shindo, S. Sato, T. Miyakoshi and K. Nagai, J. Membr. Sci., 2013, 430, 211222.

28 H. Rabiee, A. Ghadimi and T. Mohammadi, J. Membr. Sci., 2015, 476, 286-302.

29 L. Yao, C. Wu, Z. Yang, W. Qiu, P. Cui and T. Xu, J. Appl. Polym. Sci., 2012, 124(S1), E216-E224.

30 A. Wolińska-Grabczyk, J. Membr. Sci., 2006, 282(1), 225-236.

31 L. M. Ramenskaya and E. P. Grishina, J. Mol. Liq., 2016, 218, 133-137.

32 H. Sifaoui, A. Ait-Kaci, A. Modarressi and M. Rogalski, Thermochim. Acta, 2007, 456(2), 114-119.

33 S. J. Lue and S. H. Peng, J. Membr. Sci., 2003, 222(1), 203-217. 34 T. Uragami, D. Wakita and T. Miyata, eXPRESS Polym. Lett., 2010, 4(11), 33-48.

35 T. Uragami, E. Fukuyama and T. Miyata, J. Membr. Sci., 2016, 510, 131-140.

36 M. Amani, S. Amjad-Iranagh, K. Golzar, G. M. M. Sadeghi and H. Modarress, J. Membr. Sci., 2014, 462, 28-41.

37 O. Okeowo, S. Y. Nam and J. R. Dorgan, J. Appl. Polym. Sci., 2008, 108(5), 2917-2922.

38 Q. F. An, J. W. Qian, Q. Zhao and C. J. Gao, J. Membr. Sci., 2008, 313(1-2), 60-67.

39 N. Wang, T. Wu, L. Wang, X. Li, C. Zhao, J. Li and S. Ji, Sep. Purif. Technol., 2017, 179, 225-235.

40 H. Sun, L. Lu, F. Peng, H. Wu and Z. Jiang, Sep. Purif. Technol., 2006, 52(2), 203-208. 